\title{
sciendo
}

\section{Activity of Trunk and Lower Extremity Musculature: Comparison Between Parallel Back Squats and Belt Squats}

\author{
by \\ Lori Joseph ${ }^{1}$, Josh Reilly ${ }^{1}$, Kristine Sweezey ${ }^{1}$, Robyn Waugh ${ }^{1}$, Lara A. Carlson ${ }^{2}$, \\ Michael A. Lawrence ${ }^{1}$
}

\begin{abstract}
The back squat is widely used in strength training programs. Alternatively, the belt squat has been gaining popularity since it loads the weight on the hips, as opposed to the shoulders and spine. The purpose of this study was to determine whether using a belt squat would result in less lumbar extensor activation while providing similar excitation of other prime mover and stabilizer musculature. Ten participants ( 9 males, 1 female; age $29.3 \pm 4.9$ years; body mass $96.2 \pm 17.8 \mathrm{~kg}$ ) who regularly trained both belt squats and back squats performed three sets of 5 repetitions with 100\% bodyweight for each exercise. Peak and integrated muscle activity was calculated and normalized to a maximum voluntary isometric contraction. A one-way ANOVA $(p<0.05)$ was used to compare conditions. Belt squatting decreased lumbar erector impulse (45.4\%) and peak (52.0\%) activation as compared to the back squat. Belt squatting did not alter activation of the lower extremities except for a decrease in the gluteus maximus $(35.2 \%$ impulse and $32.1 \%$ peak), gluteus medius (54.1\% impulse and $55.2 \%$ peak). Furthermore, belt squatting reduced activation of the rectus abdominus (44.3\% impulse; $31.1 \%$ peak), and external obliques (45.8\% impulse; $53.7 \%$ peak) as compared to back squatting. Our results suggest belt squatting provides similar muscular demands for the quadriceps, hamstrings, and plantar flexors, but is less demanding of trunk stabilizers, and gluteual muscles. Belt squats may be a suitable alternative to back squats in order to avoid stressing low back or trunk musculature.
\end{abstract}

Key words: low back, resistance training, EMG.

\section{Introduction}

The parallel back squat is commonly utilized to increase strength of the lower extremities and to improve athletic performance (Cormie et al., 2010; Weber et al., 2008; Wisloff et al., 2004). Still, there are many individuals who cannot perform the back squat due to weakness of the core muscles, previous low back injury, an inability to adequately use or load the upper extremities or poor technique. A possible alternative lower extremity exercise is the belt squat. Unlike a back squat, the belt squat places the load at the pelvis, bypassing the need to support the load with the upper extremities, upper back, and trunk.
Although squatting is common, it also carries a higher risk of injury than most exercise, and has been found to be an exercise that leads to complaints of lower back injury and discomfort (Muller, 1999). During half squats loads as high as 6-10 times body weight on L3-L4 have been reported (Cappozzo et al., 1985). Alternatively, it has been suggested that utilizing a belt squat machine allows for a resisted squat, without excess loading of the spine (Clark et al., 2012). To date, no study has attempted to quantify the differences in low back stress between a parallel back squat and a belt squat. Given that the load is applied at or just above the pelvis it is reasonable

1 - Department of Physical Therapy, University of New England, Portland, Maine, USA.

2 - The Carlson Laboratory, Portland, Maine, USA. 
that a belt squat may result in decreased muscle activity of the lower back and other trunk stabilizers, yet the extent of these differences is unknown.

Previous research found no difference in knee flexors and extensors (Evans et al., 2017; Gulick et al., 2015), hip abductors and adductors (Gulick et al., 2015), and plantarflexors and dorsiflexors (Gulick et al., 2015) between parallel back and belt squats. Interestingly, Evans et al. (2017) found a decrease in gluteus maximus activity during belt squats as compared to back squats, whereas Gulick et al. (2015) found no difference in gluteus maximus activity between exercises. Conflicting results may be due to several factors including use of a different belt squat machine and subject experience with the belt squat. Therefore, further investigation of muscle activation patterns between belt and back squats is warranted. The purpose of this study was to examine the activation of the trunk and lower extremity musculature during both barbell back and belt squats. We hypothesized that 1) activation of the lower extremities would not differ between belt squats and back squats, and 2) activation of trunk musculature would be significantly less during belt squats as compared to back squats.

\section{Methods}

\section{Participants}

Power analysis was conducted using an online sample size calculator (https://www.dssresearch.com/resources/calculato rs/sample-size-calculator-average/). Means and standard deviations of integrated lumbar erector muscle activity from five participants who were unfamiliar with the belt squat were input into the calculator. With a power of 0.50 and an alpha level of 0.05 the determined sample size was to be 2 participants. Ten healthy individuals currently resistance training and implementing both back squats and belt squats into their training ( 9 males, 1 female; age $29.3 \pm 4.9$ years; body mass $96.2 \pm$ $17.8 \mathrm{~kg}$; body height $1.78 \pm 0.08 \mathrm{~m}$ ) volunteered for this investigation. Participants were excluded if they had sustained any musculoskeletal injuries within the past six months or if they had less than six months of experience with either the back or belt squats. This study was approved by the University of New England's Institutional Review
Board and all participants gave written informed consent

\section{Measures}

Surface electromyography (EMG) sensors (Noraxon, Scottsdale, AZ) were applied to the right side of the body of all participants at the following sites: rectus femoris (RF), vastus lateralis (VLat), vastus medialis obliquus (VMO), biceps femoris (BF), gluteus maximus (GMax), gluteus medius (GMed), adductors (ADD), medial gastrocnemius (Gastroc), tibialis anterior (TibA), lumbar extensors (LEs), rectus abdominus (RA), and external oblique (EO). EMG sensors were placed using the SENIAM recommendations (Freriks and Hermens, 1999; Hermens et al., 1999). A maximum voluntary isometric contraction (MVIC) was recorded for each participant by having them assume their squat stance with a barbell placed across their back and press into stationary pins for five seconds at $75 \%$ of their standing height.

\section{Design and Procedures}

All testing occurred in the same session. Participants were randomly assigned to either the belt or back squat for their first exercise. A standard barbell and plates were used for the back squat and belt squats were performed on a Wenning Strength belt squat machine (WenningStrength, Columbus, $\mathrm{OH}$ ). A Logitech HD C270 webcam (Logitech, Newark, CA) was set up on the right side to record a reference video and assure quality of the movement. A metronome was used to ensure participants maintained a two second concentric, and a two second eccentric phase for all repetitions. Each participant chose their preferred foot stance and tape was placed around the foot for consistent placement throughout both exercises. As per manufacturer instructions, for the belt squat the ankles were aligned with the belt attachment point and the height was adjusted so the tongue was parallel with the floor when the participant was standing upright. Participants warmed-up performing squats for four sets of 5 repetitions with a progressive increase in the load, beginning with bodyweight (no equipment), and then increasing the load to $25 \%, 50 \%$, and $75 \%$ body weight. The warm-up was repeated before both conditions. Participants then completed three sets of 5 repetitions with a $100 \%$ bodyweight load. Participants rested for three minutes between 
each set of squats, and five minutes before transitioning to the second exercise.

\section{Data Processing}

All data analyses were performed using Visual 3D software (C-Motion, Germantown, MD). Muscle activity was normalized to the MVIC. A linear envelop was created for all EMG data using a second-order Butterworth band pass (10-200 Hz) filter, rectifying the EMG signals, and applying a second-order Butterworth low pass filter at $6 \mathrm{~Hz}$. Each signal was then integrated using the trapezoidal rule. Peak activation levels were also calculated for each muscle.

\section{Statistical Analysis}

To assess for normality of the data, a review of the data was undertaken using visual inspection of Q-Q plots. Based on this analysis, several spurious outliers were identified and then addressed through Winsorization via imputation of the closest non-outlier value. This method was used as a conservative technique to perform an intention-to-treat analysis, as this technique more closely maintains the integrity of the outlier value when compared to other methods of imputation, such as group means (Dixon, 1960). Differences in all variables were analyzed using a one-way repeated ANOVA. Variance was also addressed via the Maulchy's test of sphericity. ANOVA's results that failed the assumption of sphericity based on the Maulchy's test were corrected using the Greenhouse-Geisser correction. All statistical analyses were conducted with SPSS v21 (IBM, Chicago, IL) with an alpha level of $p=0.05$.

\section{Results}

Back squatting resulted in significantly ( $p$ $<0.05)$ greater integrated muscle activity of the gluteus maximus (GMax), lumbar erectors (LEs), rectus abdominis (RA), external obliques (EO), and gluteus medius (GMed) (Table 1) and greater peak muscle activity of the GMax, LEs, RA, EO, GMed, and biceps femoris (BF) (Table 2). Intraclass correlations were high for all variables with a range from 0.928 to 0.999 .

Table 1

Integrated Muscle Activity $(n=10)$, Mean \pm SD, (95\% Confidence Interval), (\% MVIC)

\begin{tabular}{lcccccc}
\hline & $\begin{array}{c}\text { Lumbar } \\
\text { erectors }\end{array}$ & $\begin{array}{c}\text { Rectus } \\
\text { abdominus }\end{array}$ & $\begin{array}{c}\text { External } \\
\text { obliques }\end{array}$ & $\begin{array}{c}\text { Gluteus } \\
\text { medius }\end{array}$ & Adductors & $\begin{array}{c}\text { Tibialis } \\
\text { anterior }\end{array}$ \\
\hline & $1.30 \pm 0.64^{*}$ & $1.31 \pm 0.88^{*}$ & $1.06 \pm 0.93^{*}$ & $1.35 \pm 0.63^{*}$ & $1.33 \pm 0.84$ & $1.05 \pm 0.53$ \\
Back & $(0.93-1.85)$ & $(0.61-1.81)$ & $(0.36-1.60)$ & $(0.89-2.34)$ & $(0.40-2.69)$ & $(0.73-1.41)$ \\
Squat & & & & & & \\
& & & & & & \\
& $0.71 \pm 0.38$ & $0.73 \pm 0.38$ & $0.58 \pm 0.33$ & $0.62 \pm 0.36$ & $1.12 \pm 0.51$ & $0.75 \pm 0.49$ \\
Belt & $(0.47-0.95)$ & $(0.46-0.95)$ & $(0.30-0.76)$ & $(0.40-0.85)$ & $(0.55-1.90)$ & $(0.46-1.09)$ \\
Squat & & & & & & \\
\hline
\end{tabular}

\begin{tabular}{lcccccc} 
& $\begin{array}{c}\text { Gluteus } \\
\text { maximus }\end{array}$ & Rectus femoris & $\begin{array}{c}\text { Vastus } \\
\text { lateralis }\end{array}$ & $\begin{array}{c}\text { Vastus } \\
\text { medialis }\end{array}$ & $\begin{array}{c}\text { Biceps } \\
\text { femoris }\end{array}$ & Gastrocnemius \\
\hline $\begin{array}{l}1.05 \pm 0.52^{*} \\
(0.76-1.61)\end{array}$ & $2.05 \pm 1.16$ & $1.74 \pm 0.79$ & $2.17 \pm 1.82$ & $2.10 \pm 1.42$ & $0.91 \pm 0.53$ \\
Back & & $(1.28-2.77)$ & $(1.27-2.30)$ & $(0.92-3.26)$ & $(1.14-2.96)$ & $(0.60-1.29)$ \\
Squat & & & & & & \\
& $0.68 \pm 0.38$ & $1.88 \pm 1.12$ & $1.59 \pm 0.61$ & $2.04 \pm 1.46$ & $1.82 \pm 1.45$ & $0.66 \pm 0.53$ \\
Belt & $(0.44-1.13)$ & $(1.10-2.55)$ & $(1.23-2.06)$ & $(0.98-2.90)$ & $(0.88-2.27)$ & $(0.32-0.99)$ \\
Squat & & & & & & \\
\hline
\end{tabular}

*Significantly $(p>0.05)$ greater than Belt Squat; $S D=$ Standard deviation; MVIC = Maximum voluntary isometric contraction 


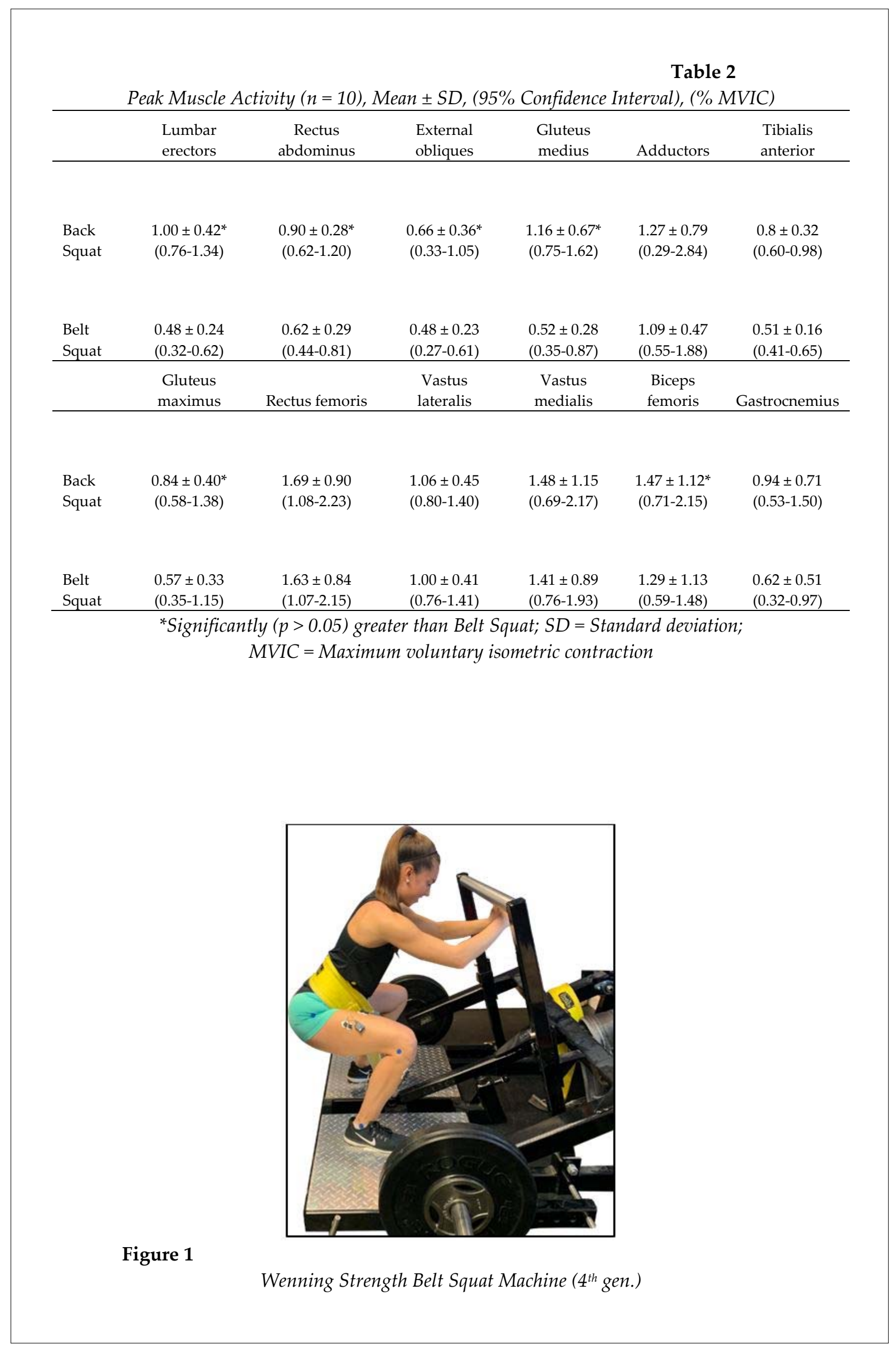




\section{Discussion}

The purpose of this study was to determine whether belt squats reduced the stress on the lower back musculature, and if activation of trunk and lower extremity musculature was different between belt squats and parallel back squats. Our paramount finding revealed that performing the belt squat decreased LEs impulse (45.4\%) and peak (52.0\%) activation as compared to the parallel back squat. The results confirmed that utilizing a belt squat did not alter activation of the lower extremities except for a decrease in the GMax (35.2\% impulse and 32.1\% peak), GMed (54.1\% impulse and 55.2\% peak) and BF (12.2\% peak). As a whole, our findings of decreased GMax activation (Evans et al., 2017) and no difference in quadriceps activation (Evans et al., 2017; Gulick et al., 2015) are consistent with previous research.

The most obvious difference between back and belt squats is how the load is applied to the person. By utilizing a belt to apply the load to the pelvis, the upper back and trunk musculature is bypassed. Our study supported this as belt squatting resulted in a large decrease in activation for LE (45.4\% impulse; $52.0 \%$ peak), RA (44.3\% impulse; $31.1 \%$ peak), and EO (45.8\% impulse; $53.7 \%$ peak) as compared to back squatting. The decreases in activation suggest that belt squats are not as challenging for the trunk musculature as back squatting. However, bypassing the trunk musculature could be advantageous for those who may not want to stress the low back and trunk musculature, but still perform a type of squatting exercise for the lower extremities.

Similar to Evans et al. (2017), we observed a decrease in GMax activation during belt squats as impulse and peak decreased $(35.2 \%$ and $32.1 \%$, respectively). This is likely due the load being closer to the hip joint, reducing the external moment arm, and thus, decreasing the muscular force required from the hip extensors. Conversely, our findings of decreased GMax activity differed from previous work by Gulick et al. (2015). The belt squat machine tested by Gulick et al. (2015) operated by allowing the weight to slide along a fixed rod, whereas in this investigation and that by Evans et al. (2017), where both observed decreased GMax activation, the load rotated about a pivot. Furthermore, previous literature has shown that when the resistance is along a fixed track, muscle activation is significantly less than a free weight back squat (Schwanbeck et al., 2009). We also observed a moderate $(12.2 \%)$ decrease in peak BF activation while performing a belt squat. However, integrated BF activity was not different between exercises, which is consistent with previous literature (Gulick et al., 2015), and suggests overall BF effort is no different between the belt squat and the back squat. Finally, we observed no significant difference between VLat, $\mathrm{RF}$, and VMO between exercises, which is consistent with previous literature (Evans et al., 2017; Gulick et al., 2015). Our findings combined with previous investigations suggest performing belt squats instead of back squats would require similar effort from the quadriceps and hamstrings. However, we would concur with the recommendations of Evans et al. (2017) that if belt squats were to replace back squats in a workout, additional exercises to target the GMax would be warranted.

The belt squat machine not only places the load closer to the pelvis, but also lowers the center of mass of the person - a load system. Lowering the center of mass increases the stability of the system. This, combined with the anchoring effect provided by the attachment to the machine, may make it easier to stabilize oneself during a belt squat as opposed to a back squat. However, no change in plantarflexor or dorsiflexor activity was observed, suggesting that participants were not challenged any more or less between belt and back squat exercises. There was a large decrease in GMed impulse (54.1\%) and peak (55.2\%) activation as compared to back squats, suggesting less of a need to generate hip abduction torque throughout the belt squat, which may be related to belt squats being more stable than back squats.

Our study was the first to quantify differences in trunk muscle activation between belt squats and barbell back squats. The results of our study should be applied carefully, as there are some limitations. We did not perform a kinematic comparison between the back and belt squat exercises, and therefore, we are unable to state that the two exercises have similar movement patterns. For example, we believe that full hip extension was not achieved during the belt squat exercise, which may impact the GMax activity; however, we are not able to report this in a meaningful fashion. It should be noted that 
participants were not allowed to utilize the handle to steady themselves or assist them during belt squats. Rather participants were asked to hold their hands hovering above the bar or to lightly rest them on the top of the bar. It is possible that if participants were allowed to grasp the handle and use their upper extremities to assist with the motion that muscle activity may be altered.

The results of this study support using the belt squat to train the quadriceps and hamstrings similarly to a back squat, yet with much less stress on the lower back and trunk musculature.
However, due to the design of the belt squat machine, hip extensor (specifically the gluteus maximus) activation is decreased and may not be strengthened as effectively as with a parallel barbell back squat. Utilizing a belt squat machine may be beneficial for those wishing to avoid placing stress on the trunk musculature or those with upper extremity mobility issues that still wish to strengthen the lower extremity musculature.

\section{Acknowledgements}

The authors would like to thank Jacked and Jilled gym for the use of their equipment and space.

\section{References}

Cappozzo A, Felici F, Figura F, Gazzani F. Lumbar spine loading during half-squat exercises. Med Sci Sports Exerc, 1985; 17(5): 613-620

Clark DR, Lambert MI, Hunter AM. Muscle activation in the loaded free barbell squat: a brief review. J Strength Cond Res, 2012; 26(4): 1169-1178

Cormie P, McGuigan M, Newton RU. Adaptations in athletic performance after ballistic power versus strength training. Med Sci Sports Exerc, 2010; 42(8): 1582-1598

Dixon WJ. Simplified Estimation from Censored Normal Samples. The Annals of Mathematical Statistics, 1960; 31: 385-391

Evans TW, McLester CN, Howard JH, McLester JR, Calloway JP. A comparison of muscle activation between back squats and belt squats. J Strength Cond Res, 2017; Jul; 33 Suppl 1: S52-S59

Freriks B, Hermens HJ. SENIAM 9: European Recommendations for Surface ElectroMyoGraphy, results of the SENIAM project: Roessingh Research and Development b.v.; 1999

Gulick DT, Fagnani JA, Gulick CN. Comparison of muscle activation of hip belt squat and barbell back squat techniques. Isokinetics and Exercise Science, 2015; 23(2): 101-108

Hermens HJ, Freriks B, Merletti R, Hagg G, Stegeman DF, Blok J, Rau G, Disselhorst-Klug C. European Recommendations for Surface ElectoMyoGraphy: Roessingh Research and Development b.v.; 1999

Muller R. Fitness centeres injury and discomfort in training. Federal Institute for Injury Prevention. Bern, Switzerland, BFU; 1999

Schwanbeck S, Chilibeck P, Binsted G. A comparison of free weight squat to Smith machine squat using electromyography. J Strength Cond Res, 2009; 23(9): 2588-2591

Weber, KR, Brown, LE, Coburn, JWZinder, SM. Acute effects of heavy-load squats on consecutive squat jump performance. J Strength Cond Res, 2008; 22(3): 726-730

Wisloff U, Castagna C, Helgerud J, Jones R, Hoff J. Strong correlation of maximal squat strength with sprint performance and vertical jump height in elite soccer players. Br J Sports Med, 2004; 38(3): 285-288

\section{Corresponding author:}

\section{Michael Lawrence, MS}

University of New England, 716 Stevens Ave; Portland, ME 04103

Phone: (207) 221-4274

Fax: (207) 523-1910

E-mail: mlawrence3@une.edu 